\title{
ARTICLE Projection-specific deficits in synaptic transmission in adult Sapap3-knockout mice
}

\author{
Lotfi C. Hadjas ${ }^{1}$, Michael M. Schartner ${ }^{1}$, Jennifer Cand ${ }^{1}$, Meaghan C. Creed ${ }^{1}{ }^{1}$, Vincent Pascoli ${ }^{1}$, Christian Lüscher $\mathbb{D}^{1,2}$ and \\ Linda D. Simmler (iD)
}

\begin{abstract}
Obsessive-compulsive disorder (OCD) is a circuit disorder involving corticostriatal projections, which play a role in motor control. The Sapap3-knockout (KO) mouse is a mouse model to study OCD and recapitulates OCD-like compulsion through excessive grooming behavior, with skin lesions appearing at advanced age. Deficits in corticostriatal control provide a link to the pathophysiology of OCD. However, there remain significant gaps in the characterization of the Sapap3-KO mouse, with respect to age, specificity of synaptic dysfunction, and locomotor phenotype. We therefore investigated the corticostriatal synaptic phenotype of Sapap3-KO mice using patch-clamp slice electrophysiology, in adult mice and with projection specificity. We also analyzed grooming across age and locomotor phenotype with a novel, unsupervised machine learning technique (MoSeq). Increased grooming in Sapap3-KO mice without skin lesions was age independent. Synaptic deficits persisted in adulthood and involved the projections from the motor cortices and cingulate cortex to the dorsolateral and dorsomedial striatum. Decreased synaptic strength was evident at the input from the primary motor cortex by reduction in AMPA receptor function. Hypolocomotion, i.e., slowness of movement, was consistently observed in Sapap3-KO mice. Our findings emphasize the utility of young adult Sapap3-KO mice to investigate corticostriatal synaptic dysfunction in motor control.
\end{abstract}

Neuropsychopharmacology (2020) 45:2020-2029; https://doi.org/10.1038/s41386-020-0747-3

\section{INTRODUCTION}

Humans constantly execute complex motor behaviors, which serve basic processes such as eating or walking, or elaborate skills like riding a bicycle. In obsessive-compulsive disorder (OCD) aberrant control over motor outputs, either through excessive habits [1] or as response to obsessions [2], determines compulsive symptoms such as nail biting. The execution of motor behavior is controlled by top-down projections from cortical areas to the dorsal striatum (caudate putamen in primates), which form strong excitatory synaptic connections onto striatal output neurons [3-5]. The postsynaptic density (PSD) harbors excitatory neurotransmitter receptors and essential structural proteins including the SAP90/PSD95-associated protein 3 (SAPAP3, also DLGAP3 or GKAP3) [6].

Mice with a constitutive knockout (KO) of Sapap3 show complex behavioral phenotypes, which manifest as compulsive, OCD-like behaviors. Sapap3-KO mice have therefore been used as an animal model to study OCD. Construct validity for this disease model is supported by more frequent SAPAP3 mutations in OCD patients than in healthy controls [7]. Particularly pathological body care such as nail biting seems to be associated with SAPAP3 mutations [8]. OCD also manifests with intrusive, distressing thoughts which obviously escape investigation in mice, but compulsive-like motor phenotypes of Sapap3-KO mice are well-suited to preclinically investigate OCD. Such phenotypes are excessive grooming [9-11], anxiety-like behavior $[9,12]$, behavioral inflexibility $[13,14]$, and deficits in the balance of habitual and goal-directed behavior $[15,16]$. Excessive grooming can be alleviated with clinically effective treatments (i.e., the pharmacological compound fluoxetine [9] and deep brain stimulation [17]), which supports predictive validity of the mouse model.

Despite construct, face and predictive validity of the Sapap3-KO mouse model, studies that have used Sapap3-KO mice to test treatment approaches for OCD remain limited $[17,18]$. There is a need for better characterization of the model and its relevance to the clinical pathophysiology of OCD. Skin lesions arising from excessive grooming typically appear in Sapap3-KO mice at advanced age, therefore, OCD-like behavioral phenotypes have mostly been studied in mice of about 6 months or older, shortly before the onset of lesions [9, 10, 13, 14, 17]. In contrast, corticostriatal synaptic deficits have been assessed in mice aged 3-8 weeks [19-23]. Clearly, the age mismatch for behavioral and neuronal phenotypes in the Sapap3-KO model needs to be addressed, particularly given that variable expression of Sapap3 during postnatal synapse maturation has been reported [24]. Furthermore, for a thorough understanding of the pathologies in the Sapap3-KO mice, refinement of circuit specificity of synaptic dysfunction is necessary, as there are inputs (i.e., thalamic) that seem unaffected by the KO of Sapap3 [21]. Finally, recent developments in behavioral analysis [25-27] permit sophisticated examination of behavioral phenotypes based on unsupervised machine learning.

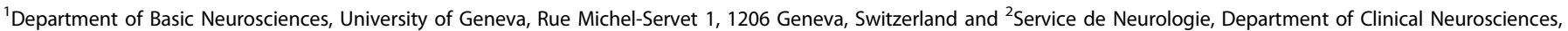
Geneva University Hospital, Rue Gabrielle-Perret-Gentil 4, 1205 Geneva, Switzerland
}

Correspondence: Linda D. Simmler (linda.simmler@unige.ch)

Received: 12 November 2019 Revised: 8 June 2020 Accepted: 9 June 2020

Published online: 25 June 2020 


\section{MATERIALS AND METHODS}

Animals

Mice were housed on a normal $12 \mathrm{~h}$ light-dark cycle (lights on at 7:00 a.m.) with ad libitum food and water. All experiments were conducted in the light cycle. The Sapap3-mutant mouse line (B6.129-Dlgap3 $3^{\text {tm1Gng }} / \mathrm{J}$ ) was provided by Dr. Gouping Feng (Massachusetts Institute of Technology). Sapap3 ${ }^{-1-}$ (KO) and Sapap3 $^{+/+}$(WT littermate controls) were generated from Sapap $^{+/-}$breeding. Breeders had been backcrossed on C57BL/ $6 \mathrm{~J}$ background for $>20$ generations. For patch-clamp experiments, Sapap $^{+1-}$ were crossed with dopamine (DA) D1-receptor (Drd1)Cre (D1-Cre; B6;129-Tg(Drd1-cre)120Mxu/Mmjax) or parvalbumin (PV) (Pvalb)-Cre lines (B6.129P2-Pvalb ${ }^{\text {tm1(cre)Arbr } / J) ~(J a c k s o n ~ L a b o r a-~}$ tory) to obtain Cre-positive Sapap $3^{+/-}$mice for breeding. Male and female mice were used. Experiments were performed with mice without skin lesions. All procedures were approved by the Institutional Animal Care and Use Committee of the University of Geneva and by the animal welfare committee of the Canton of Geneva, in accordance with Swiss law.

\section{Locomotor activity and motion sequencing}

Mice at 11-18 weeks of age were handled on 3 days prior to the experiment. For testing, mice were placed in a $40 \times 40 \mathrm{~cm}$ arena made of frosted opal-white acrylic glass, moderately illuminated (40-50 lx). After $30 \mathrm{~min}$ of habituation, top-down videos were acquired during $20 \mathrm{~min}$ with a conventional webcam and with a 3D sensor (Kinect version 2, Microsoft). Locomotor activity as distance traveled and mobility/immobility time was analyzed using the Anymaze software. To count blocks of immobility, we defined a block as immobility lasting minimum $1 \mathrm{~s}$ and being terminated by mobility lasting minimum $1 \mathrm{~s}$. Motion sequencing (MoSeq) was processed from the 3D videos as reported by Wiltschko et al. [25] using their code with slight modifications. We adjusted the python scripts for mouse detection, taking into account differences between the Kinect sensors version 2 and 1, since the python code was initially written for version 1 . The code and documentation are accessible through Dr. Sandeep Robert Datta (Harvard Medical School).

\section{Grooming}

Grooming was assessed either in an empty cage without bedding (mice aged 7-25 weeks without skin lesions; for experiment presented in Fig. 1) or from videos recorded in parallel to the 3D video recordings for MoSeq (for experiment presented in Fig. 5). For both experiments, mice were handled on 3 days prior to the experiment. To assess grooming in the empty cage, mice were habituated to the cage for $20 \mathrm{~min}$. Then, a 5-min side-view video was recorded. Grooming in the open field was scored from topview videos also used to analyze locomotion. An experimenter, blinded to genotype, scored grooming manually. Grooming behavior (i.e., licking or brushing of paws, back, belly, or tail) in bouts with $>2 \mathrm{~s}$ duration was counted, similar to previous studies which used $3 \mathrm{~s}$ minimum grooming duration as cutoff $[9,12]$. We scored grooming bouts of $<2 \mathrm{~s}$ as "tic-like" grooming and included them in an extended analysis (see Supplementary information).

\section{Stereotactic injections}

Viruses were injected using standard stereotactic surgeries. AAV5CamKIla-ChR2(H134R)-eYFP was injected at (from bregma and dura mater) +1.35 AP, $\pm 1.25 \mathrm{ML},-0.75 \mathrm{DV}$ for M1/M2 (200 nL), at $+1.8 \mathrm{AP}, \pm 0.5 \mathrm{ML},-0.6 \mathrm{DV}$ for Cg1/M2 (150 nL), and at $+2.6 \mathrm{AP}$, $\pm 1.5 \mathrm{ML},-2.0 \mathrm{DV}$ for OFC ( $400 \mathrm{~nL})$. Five weeks later, a second virus (AA5-EF1a-DIO-mCherry) was injected to visualize cell types in a Cre-dependent manner. Coordinates were +1.0 AP, $\pm 2.2 \mathrm{ML}$, $-2.25 /-2.0 \mathrm{DV}$ (300 $\mathrm{nL}$ at each DV location) for DLS, $+1.1 \mathrm{AP}, \pm 1.5$ $\mathrm{ML},-2.5 /-2.25 \mathrm{DV}$ for DMS, and +1.1 AP, $\pm 2.0 \mathrm{ML},-3.0 / 2.7 /-2.5$ DV (200 $\mathrm{nL}$ at each DV location) for central striatum. For electrical stimulation and recordings of $\mathrm{PV}^{+}$cells, only the second virus was injected, in the dorsolateral and central striatum, respectively. All viruses were from UNC Vector core.

\section{Slice electrophysiology}

Slice electrophysiology was conducted as described elsewhere [28]. In brief, whole-cell patch-clamp recordings were conducted at $30^{\circ} \mathrm{C}$ in artificial cerebrospinal fluid (aCSF) containing picrotoxin $(100 \mu \mathrm{M})$. Where indicated, $\mathrm{CaCl}_{2}$ in the aCSF was replaced with $2 \mathrm{mM} \mathrm{SrCl}{ }_{2}$. For electrically and optogenetically evoked currents, stimuli were applied every $10 \mathrm{~s}$ and traces were used for quantification after stabilization of response (typically 5-10 min after obtaining whole-cell configuration). For PPR, two stimuli were applied $50 \mathrm{~ms}$ apart and 5-10 traces were averaged. For isolated AMPA receptor (AMPAR) currents 2-amino-5phosphonopentanoic acid (AP-5; $50 \mu \mathrm{M})$ was bath-applied. Rectification index (RI) was calculated as AMPAR chord conductance at $-70 \mathrm{mV}$ divided by the chord conductance at $40 \mathrm{mV}$. In NMDAR experiments $10 \mu \mathrm{M}$ NBQX was bath-applied. Miniature EPSCs were recorded at $-70 \mathrm{mV}$ in the presence of $0.5 \mu \mathrm{M}$ tetrodotoxin. In recordings for asynchronous release ( $\mathrm{Sr}^{2+}$-aCSF), events were analyzed $20-200 \mathrm{~ms}$ post light stimulation. The internal solutions were made of (in $\mathrm{mM}$ ) $130 \mathrm{CsCl}, 4 \mathrm{NaCl}, 5$ creatine phosphate, 2 $\mathrm{MgCl}_{2}, 2 \mathrm{Na}_{2} \mathrm{ATP}, 0.6 \mathrm{Na}_{3} \mathrm{GTP}, 1.1$ EGTA, 5 HEPES, 5 QX-314, 0.1 spermine and (for recordings in $\mathrm{Sr}^{2+}$-aCSF) 140 potassium gluconate, 10 creatine phosphate, $2 \mathrm{MgCl}_{2}, 4 \mathrm{Na}_{2} \mathrm{ATP}, 0.3 \mathrm{Na}_{3} \mathrm{GTP}$, 0.2 EGTA, 10 HEPES, $5 \mathrm{KCl}$.

\section{Immunostaining}

Mice aged 15 weeks were transcardially perfused under pentobarbital anesthesia with $4 \%$ paraformaldehyde. A standard immunostaining procedure was used. Incubation with rabbit anti-PV antibody $\left(1: 500\right.$, Swant, PV27) was overnight at $4{ }^{\circ} \mathrm{C}$, followed by incubation with Alexa 488 goat antirabbit antibody (1:500, Invitrogen, A1108) for $2 \mathrm{~h}$ and Hoechst (1:1000) for $1 \mathrm{~h}$ at room temperature. Images were acquired at $\times 10$ magnification with a widefield scanner (Axio Scan.Z1, Zeiss). Fluorescent cells were automatically counted using the software MetaMorph. The dimensions of the counted regions of interest (ROI) were $1030 \times$ 1070 pixels for striatal areas, $1230 \times 1870$ pixels for the primary motor cortex (M1) and $1180 \times 1720$ pixels for the primary somatosensory cortex (S1). Cell counts in each brain area were averaged per mouse.

\section{Statistical analysis}

Data were tested for normal distribution to determine if parametric (normally distributed data) or nonparametric (if data did not pass the Shapiro-Wilk normality test) comparison was indicated. For comparison of two groups, unpaired Student's $t$ test or Mann-Whitney test were performed. Otherwise ANOVA was performed, followed by Sidak post-hoc analysis if ANOVA resulted in a significant main genotype effect or significant interaction. Details of statistical tests and number of experimental replicates are noted in the figure legends. Drawings of mouse brain sections were modified from Paxinos and Franklin [29].

\section{RESULTS}

Increased grooming in young adult Sapap3-KO mice First, we tested how the Sapap3-KO grooming phenotype $[9,10,22]$ evolves with age (Fig. 1a). Overall Sapap3-KO showed significantly elevated grooming time $\left(p=5 \times 10^{-5}\right.$, Mann-Whitney comparison; mean grooming time (within a 5min test period) averaged across tested age range ( \pm SD): $30 \mathrm{~s} \pm 39$ for WT and $95 \mathrm{~s} \pm 74$ for $\mathrm{KO}, \mathrm{N}=23 \mathrm{WT}$ and $39 \mathrm{KO}$ ). However, there was no correlation between age and time spent grooming (Fig. 1b) or age and number of grooming bouts (Fig. 1c) for the Sapap3-KO. Including "tic-like" grooming of $<2 \mathrm{~s}$ in the analysis did not change the finding of age independence (Fig. S1). Our 
a

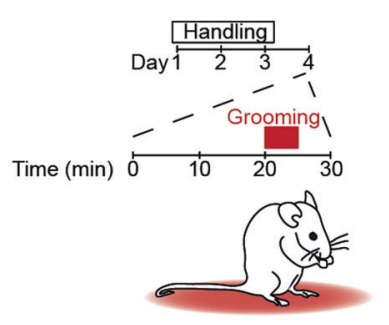

b

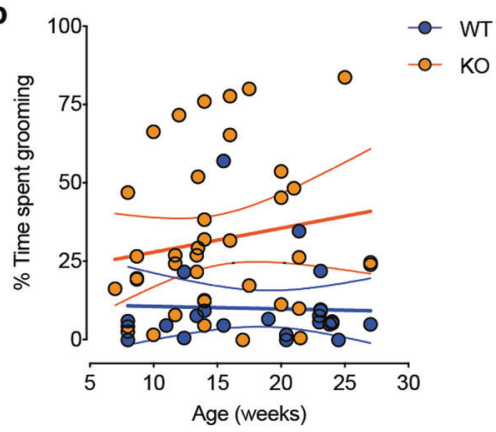

C

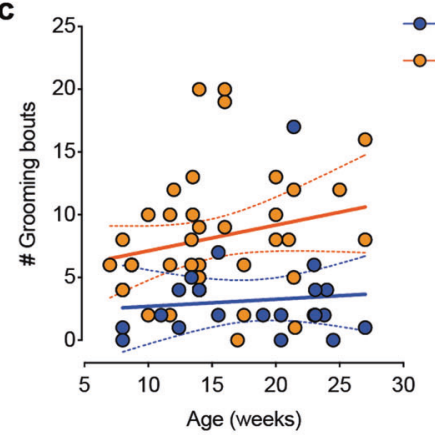

d

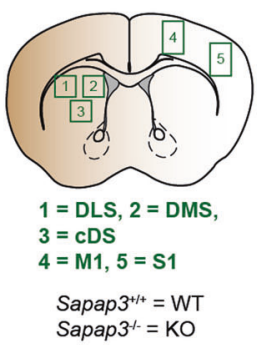

e

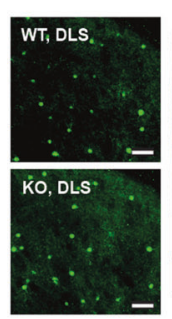

PV immunostaining

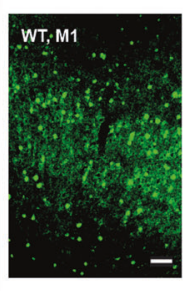

f

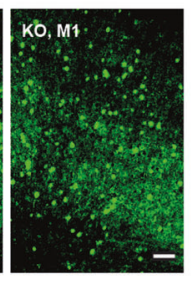

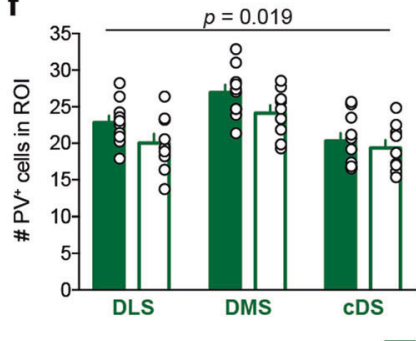

g

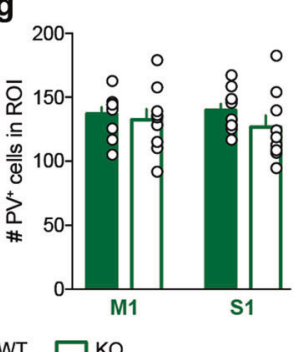

h

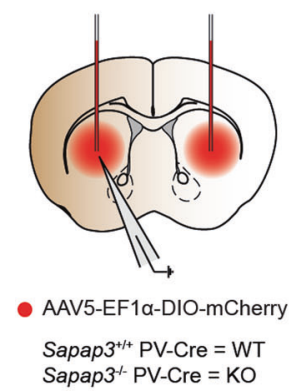

i $\quad W T, P V+$ cell

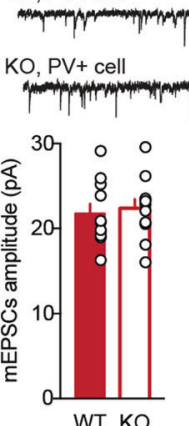

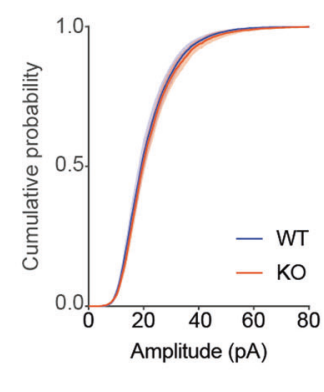

j
WT KO k

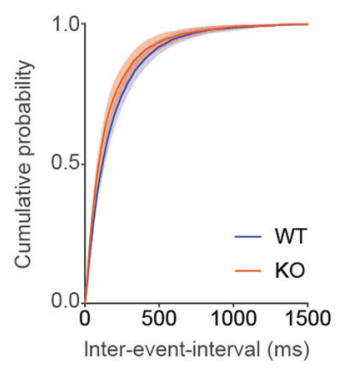

Fig. 1 Excessive grooming across age in Sapap3-KO mice, but no major genotype effect on PV $^{+}$cells in the striatum. a Experimental paradigm to evaluate grooming across age. b Time spent grooming (\%) vs. age. Grooming bouts of minimum $2 \mathrm{~s}$ duration were considered. Linear regression was not significant either for WT or for KO animals. $R^{2}(\mathrm{WT})=0.0013, R^{2}(\mathrm{KO})=0.027, p(\mathrm{WT})=0.87, p(\mathrm{KO})=0.31 ; N=23 \mathrm{WT}$, $39 \mathrm{KO}$. Lines are best fit with $95 \%$ confidence bands. c Number of grooming bouts in 5 min vs. age. Grooming bouts of minimum $2 \mathrm{~s}$ duration were considered. Linear regression was not significant either for WT or for KO animals. $R^{2}(\mathrm{WT})=0.010, R^{2}(\mathrm{KO})=0.063, p(\mathrm{WT})=0.65, p(\mathrm{KO})=$ 0.12; $N=22$ WT, $39 \mathrm{KO}$. Lines are best fit with $95 \%$ confidence bands. d Quantification of parvalbumin-containing ( $\mathrm{PV}^{+}$) cells in the dorsolateral, dorsomedial, and centromedial striatum (DLS, DMS, and CDS), motor cortex 1 (M1) and somatosensory cortex 1 (S1). e Representative pictures of immunostained $\mathrm{PV}^{+}$cells. Scale bars are $100 \mu \mathrm{m}$. f Number of $\mathrm{PV}^{+}$cells in the striatal regions of interests (ROls). Values are average counts from six ROls per animal. There was a significant main genotype difference $(F(1,51)=5.873, p=0.019)$, but no significant differences in the post-hoc test. Two-way ANOVA with Sidak post-hoc test, $N=10$ WT, 9 KO. g Number of PV ${ }^{+}$cells in M1 and S1. The number of $\mathrm{PV}^{+}$cells was not significantly different between Sapap3-KO and WT littermates. $F(1,34)=1.572, p=0.22$, two-way ANOVA, $N=10 \mathrm{WT}, 9 \mathrm{KO}$. $\mathbf{h}$ Schematic of virus injection and location for patch-clamp recordings. Mice were Sapap3-KO or WT littermates expressing PV-Cre. i Representative traces of mEPSCs recorded in PV ${ }^{+}$cells (top). Scale bar is $0.2 \mathrm{~s}, 50 \mathrm{pA}$. Mean mEPSC amplitude (bottom left) and mean mEPSC frequency (bottom right) did not differ between genotypes. $P$ (amplitudes) $=0.7, p$ (frequency) $=0.2$, unpaired $t$-test, $N$ (cells) $=11 \mathrm{WT}$, $11 \mathrm{KO}$. j Cumulative probability for mEPSC amplitudes. $P=0.09$, Kolmogorov-Smirnov comparison, $N$ (cells) $=11 \mathrm{WT}, 11 \mathrm{KO}$. k Cumulative probability for mEPSC inter-event intervals. $P=0.054$, Kolmogorov-Smirnov comparison, $N$ (cells) $=11 \mathrm{WT}, 11 \mathrm{KO}$. Data are mean $\pm \mathrm{SEM}$.

experiments suggest that excessive grooming occurs in Sapap3KO mice independent of age.

No major $\mathrm{PV}^{+}$-cell abnormalities in young adult Sapap3-KO mice Next, we aimed to characterize the corticostriatal neural and synaptic deficits of Sapap3-KO in young adult mice. Genotypedependent synaptic differences has been shown for mice at weaning age and adolescence $[9,19,20,22]$, and changes in $\mathrm{PV}^{+}$ cell abundance in advanced adulthood [11], but it is unclear if these neural deficits also exist in young adult Sapap3-KO mice. First, we quantified the abundance of $\mathrm{PV}^{+}$cells in three different brain areas (Fig. 1d). Immunoreactive ( $\mathrm{PV}^{+}$; Fig. 1e) cell counts are displayed as average per mouse and brain area (Fig. 1f, g). Across striatal areas (Fig. 1f) we found a significant main genotype effect in the ANOVA, however, post-hoc analysis was not significant. This trend is consistent with reduced striatal $\mathrm{PV}^{+}$cell abundance previously reported in 3-10 months old Sapap3-KO mice [11]. No genotype differences were evident in the cortical areas M1 and S1 (Fig. 1g). 


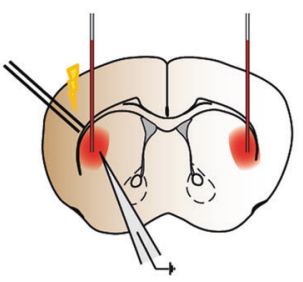

- AAV5-EF1a-DIO-mCherry Sapap $3^{+/+}$D1R-Cre $=$WT Sapap $3^{--}$D1R-Cre $=$KO

b

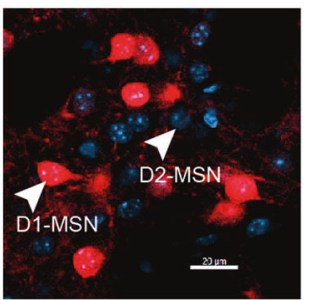

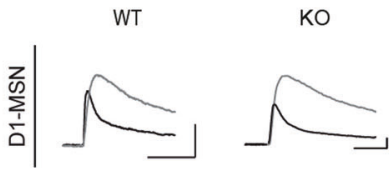
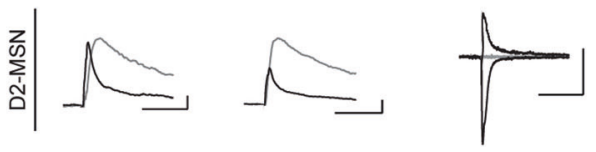

WT

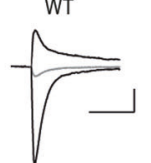

d

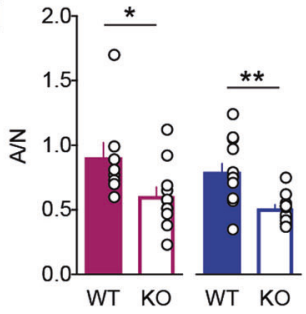

e

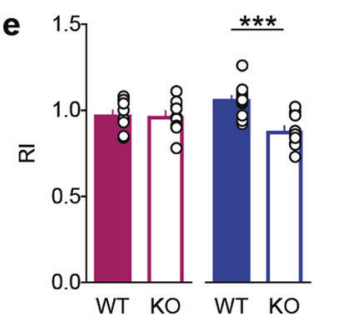

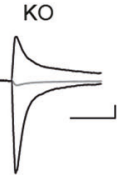

WT

$\mathrm{KO}$
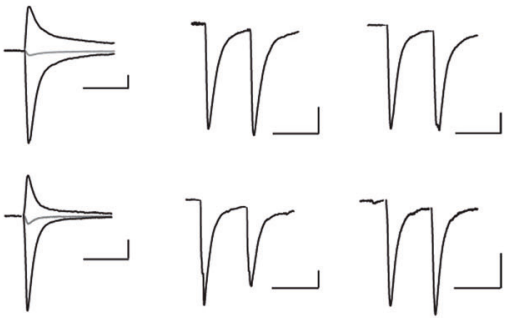

$\mathbf{f}$

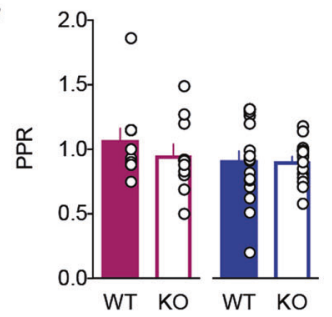

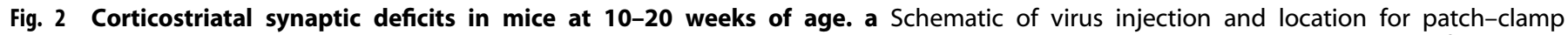

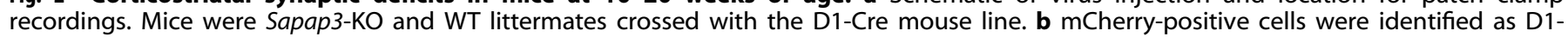

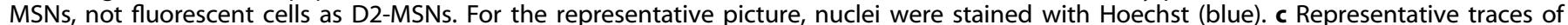

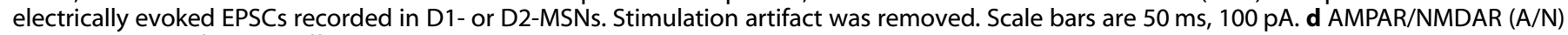

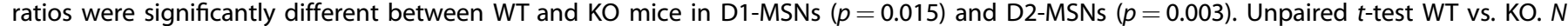

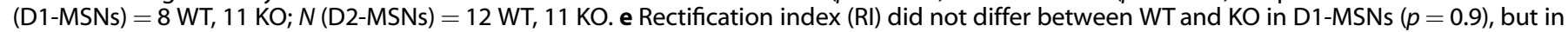

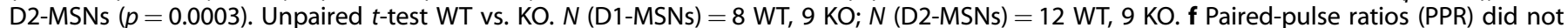

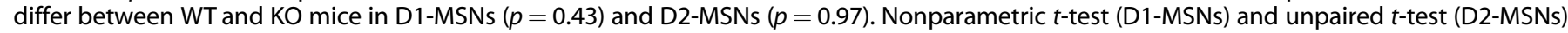
WT vs. KO. $N$ (D1-MSNs) = 10 WT, $10 \mathrm{KO}$; $N$ (D2-MSNs) = 16 WT, 15 KO. Data are mean \pm SEM.

We further asked whether Sapap3-KO affects excitatory transmission onto $\mathrm{PV}^{+}$cells in the dorsal striatum and recorded miniature excitatory postsynaptic potentials (mEPSCs) (Fig. 1h). Neither mEPSC amplitude nor frequency differed between genotypes (Fig. 1i-k).

\section{Synaptic deficits in adult Sapap3-KO}

Next, we evaluated excitatory synaptic strength in dorsolateral D1receptor and D2-receptor medium-sized spiny neurons (D1-MSNs and D2-MSNs) using electrical stimulation of the corpus callosum, to activate cortical fibers nonspecifically. Previously, decreased AMPAR vs. NMDAR currents ( $\mathrm{A} / \mathrm{N}$ ratio) have been described in 3 weeks old mice [20]. Here, we tested this preparation in adult mice of 10-20 weeks (Fig. 2a-C). A/N ratios on D1- and D2-MSNs were significantly decreased in Sapap3-KO relative to WT littermates (Fig. 2d). This showed that synaptic deficits of 3 weeks old mice [20] persist to adulthood. In the same preparation, we assessed AMPARmediated currents at negative $(-70 \mathrm{mV})$, reversal $(0 \mathrm{mV})$, and positive $(+40 \mathrm{mV})$ potentials to test for the presence of GluA2lacking AMPARs. The RI was 1 in D1-MSNs of WT and KO, indicating the absence of GluA2-lacking AMPARs (Fig. 2e). There was a small but significant genotype difference in D2-MSNs (Fig. 2e), suggesting differences in AMPAR subunit composition at this synapse, with slightly more GluA2-lacking AMRARs in the WT condition. Pairedpulse ratios (PPR), a measure for presynaptic release probability, did not differ between genotypes (Fig. 2f), which is consistent with findings from 3 weeks old mice [20]. Overall, our data suggest that the major neuronal phenotype in adult Sapap3-KO is decreased A/N ratios at excitatory corticostriatal synapses onto both MSN cell types, suggestive of reduced synaptic strength.

Input specificity of synaptic deficits

With electrical stimulation of the corpus callosum (Fig. 2), cortical fibers are targeted in a nonspecific way. We therefore next assessed synaptic properties of specific corticostriatal projections in adult mice, using channelrhodopsin-2 (ChR2) expression in cortical areas (Fig. 3a-c, g, k). At synapses from M1/M2 to dorsolateral D1- and D2-MSNs we found significantly decreased A/ $\mathrm{N}$ ratios in Sapap3-KO mice (Fig. 3d). Decreased A/N ratios were also evident at Cg1/M2-to-DMS synapses, in D1- and D2-MSNs of Sapap3-KO mice (Fig. 3h), but not at synapses of OFC-to-central striatum D1- and D2-MSNs (Fig. 3l). There were no genotype differences in RI (Fig. 3e, i, m) and PPR (Fig. 3f, j, n) at either cortical input. Comparison of absolute amplitudes (Fig. S3) indicated decreased AMPAR currents at Sapap3-KO M1/M2-to-DLS synapses, and no genotype differences in AMPAR and NMDAR currents at OFC-to-cDS synapses. Interestingly, Sapap3-KO Cg1/M2-to-DMS synapses show moderately increased AMPAR and strongly increased NMDAR current amplitudes with a net effect of decreased $\mathrm{A} / \mathrm{N}$ ratio. However, interpretations from absolute currents have to be made with caution since our experimental design did not control for ChR2 infection and stimulation light intensity. Further experiments controlling for the number of stimulated synapses are needed. Since we previously reported reduced locomotion in Sapap3-KO mice [15] and suspected an involvement of the $\mathrm{M} 1 / \mathrm{M} 2$ rather than $\mathrm{Cg} 1 / \mathrm{M} 2$ projection, we subsequently focused on the M1/M2-to-DLS to resolve directionality of AMPAR- and NMDAR-specific changes.

Decreased AMPAR currents but no changes in NMDAR subunit composition

The decreased $\mathrm{A} / \mathrm{N}$ ratios of M1/M2-to-DLS synapses indicate decreased synaptic strength, since typically it is the number of functional AMPAR, not NMDAR, that changes in the synaptic composition when synapses modify their strength [23]. However, NMDARs could also be altered in the Sapap3-KO model, as previous work suggested $[9,22]$. We therefore assessed on the M1/M2 input (Fig. 4a) potential AMPAR and NMDAR dysfunction more specifically. First, we tested for changes in AMPAR function, 
a

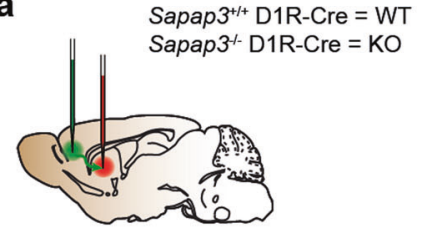

- AAV5-CamKIla-ChR2(H134R)-eYFP - AAV5-EF1a-DIO-mCherry

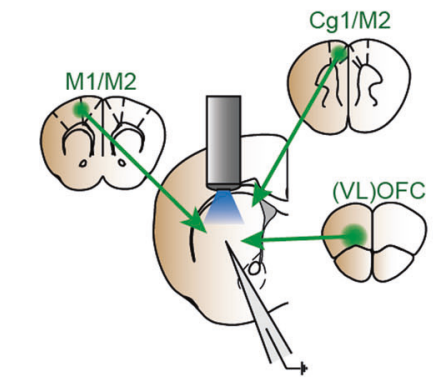

b

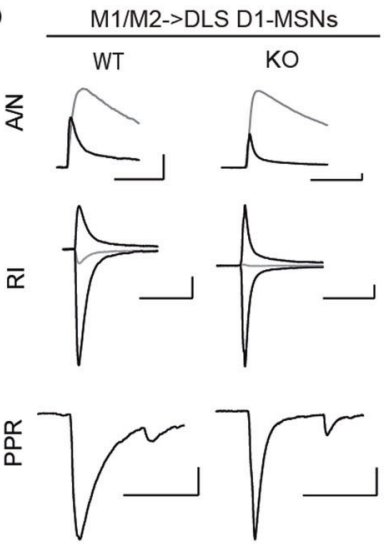

C
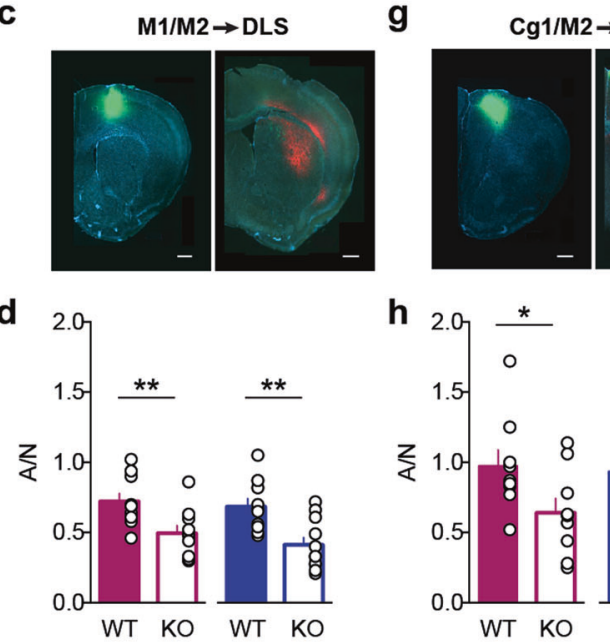

h 2

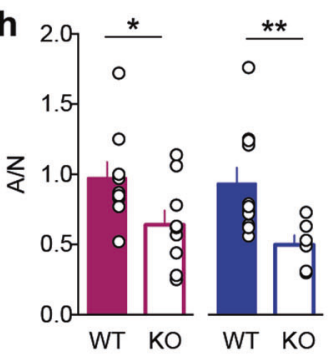

e

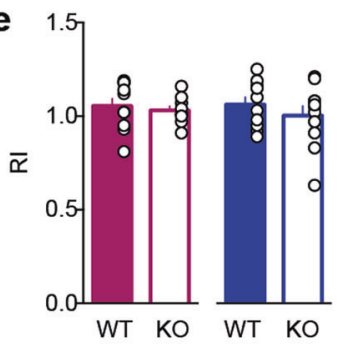

f

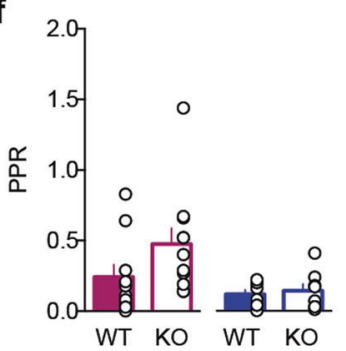

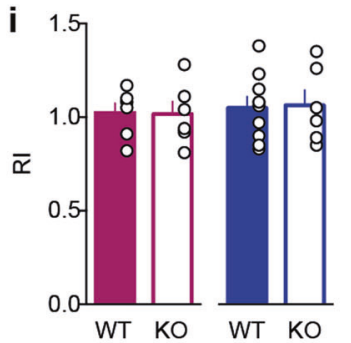

j

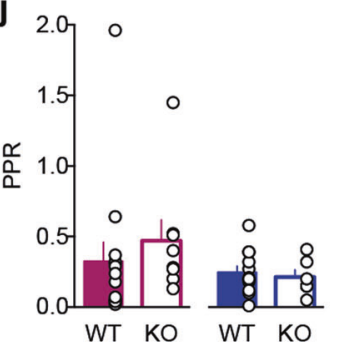

$\mathbf{k}$
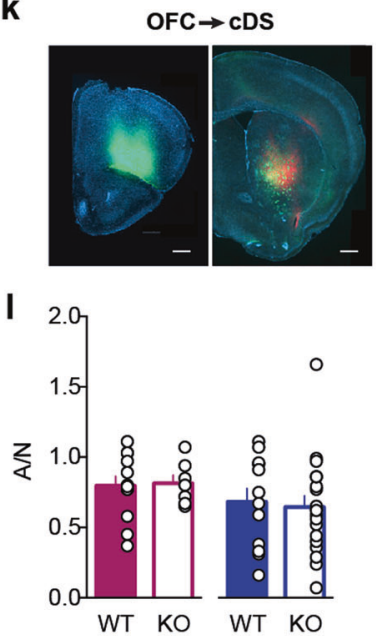

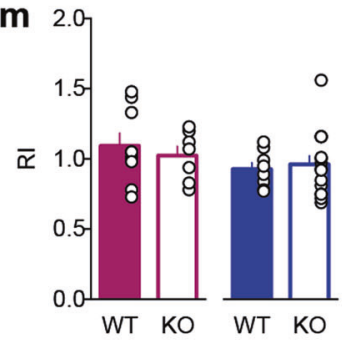

n

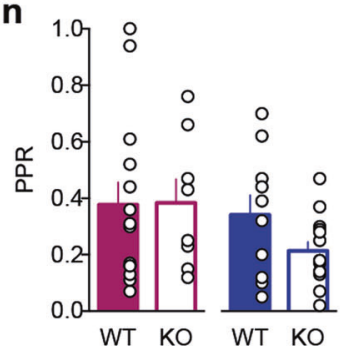

\section{$\square$ D1-MSNs $\square$ D2-MSNs}

Fig. 3 Input specificity of corticostriatal synaptic deficits in Sapap3-KO mice. a Schematic of virus injection and location for patch-clamp recordings. Mice were Sapap3-KO and WT littermates crossed with a D1-Cre mouse line. b Representative traces of light-evoked EPSCs recorded in D1-MSNs on the M1/M2 input. Scale bars are $50 \mathrm{~ms}, 100 \mathrm{pA}$. c Representative image of the ChR2 injection site in the M1/M2 (green) and mCherry expressed by D1-MSNs in the dorsolateral striatum (red). Blue is Hoechst-staining of cell nuclei. Scale bars are $500 \mu \mathrm{m}$. d AMPAR/NMDAR $(\mathrm{A} / \mathrm{N})$ ratios were significantly different between WT and KO mice in D1-MSNs $(p=0.009)$ and D2- MSNs $(p=0.003)$ at the M1/M2 input. Unpaired $t$-test WT vs. KO. $N$ (D1-MSNs) $=10$ WT, $10 \mathrm{KO} ; N$ (D2-MSNs) =10 WT, 11 KO. e Rectification index (RI) did not differ between WT and KO in D1-MSNs $(p=0.63)$ and D2-MSNs $(p=0.38)$ at the M1/M2 input. Unpaired $t$-test WT vs. KO. N (D1-MSNs) $=10$ WT, 9 KO; $N$ (D2-MSNs) $=10 \mathrm{WT}, 11 \mathrm{KO}$. f Paired-pulse ratios (PPR) did not differ between WT and KO mice in D1-MSNs $(p=0.053)$ and D2-MSNs $(p=$ 0.67 ) at the M1/M2 input. Nonparametric $t$-test (D1-MSNs) and unpaired $t$-test (D2-MSNs) WT vs. KO. $N$ (D1-MSNs) = 10 WT, 11 KO; $N$ (D2MSNs) $=8 \mathrm{WT}, 8 \mathrm{KO}$. g Same as in c, but ChR2 injection site was in the Cg1/M2 (green) and mCherry expressed by D1-MSNs in the dorsomedial striatum (red). $\mathbf{h ~ A} / \mathrm{N}$ ratios were significantly different between WT and KO mice in D1-MSNs $(p=0.045)$ and D2-MSNs $(p=0.005)$ at the Cg1/ M2 input. Unpaired t-test WT vs. KO. $N$ (D1-MSNs) $=9 \mathrm{WT}, 9 \mathrm{KO} ; \mathrm{N}$ (D2-MSNs) $=11 \mathrm{WT}, 6 \mathrm{KO}$. i Rl did not differ between WT and KO in D1-MSNs $(p=0.78)$ and D2-MSNs $(p=0.84)$ at the Cg1/M2 input. Unpaired $t$-test WT vs. KO. $N(D 1-M S N s)=7$ WT, 6 KO; $N$ (D2-MSNs) =10 WT, 6 KO. $\mathbf{j}$ PPR did not differ between WT and KO mice in D1-MSNs $(p=0.14)$ and D2-MSNs $(p=0.66)$ at the Cg1/M2 input. Nonparametric $t$-test (D1-MSNs) and unpaired $t$-test (D2-MSNs) WT vs. KO. $N(\mathrm{D} 1-\mathrm{MSNs})=14 \mathrm{WT}, 8 \mathrm{KO} ; N(\mathrm{D} 2-\mathrm{MSN})=12 \mathrm{WT}, 6 \mathrm{KO}$. $\mathbf{k}$ Same as in c, but ChR2 injection site was in the OFC (green) and mCherry expressed by D1-MSNs in the central striatum (red). I A/N ratios were not significantly different between WT and KO mice in D1-MSNs $(p=0.86)$ and D2-MSNs $(p=0.60)$ at the OFC input. Unpaired $t$-test WT vs. KO. $N(\mathrm{D} 1-\mathrm{MSNs})=12 \mathrm{WT}, 7 \mathrm{KO} ; N(\mathrm{D} 2-$ MSNs) $=12 \mathrm{WT}, 19 \mathrm{KO} . \mathbf{m}$ RI did not differ between WT and KO in D1-MSNs $(p=0.56)$ and D2-MSNs $(p=0.70)$ at the OFC input. Unpaired $t$-test WT vs. KO. $N(\mathrm{D} 1-\mathrm{MSNs})=9 \mathrm{WT}, 7 \mathrm{KO} ; N(\mathrm{D} 2-\mathrm{MSNs})=8 \mathrm{WT}, 15 \mathrm{KO} . \mathbf{n}$ PPR did not differ between WT and KO mice in D1-MSNs $(p=0.80)$ and D2-MSNs $(p=0.084)$ at the OFC input. Nonparametric $t$-test (D1-MSNs) and unpaired $t$-test (D2-MSNs) WT vs. KO. $N(D 1-M S N s)=14$ WT, 8 KO; $N(\mathrm{D} 2-\mathrm{MSNs})=10 \mathrm{WT}, 14 \mathrm{KO}$. Data are mean \pm SEM.

which directly relates to synaptic strength. We replaced $\mathrm{Ca}^{2+}$ in the recording aCSF with $\mathrm{Sr}^{2+}$ in order to record unitary events in a projection-specific manner (Fig. 4b). Such unitary events are insensitive to between-subject differences in ChR2 expression, which allows for comparison of AMPAR amplitudes in an optogenetically identified circuit. Cumulative probability analysis of amplitude revealed that M1/M2-to-DLS AMPAR currents were significantly decreased in Sapap3-KO, compared to WT 
a

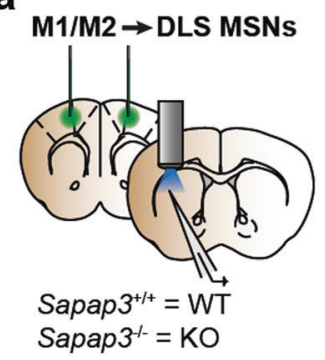

b

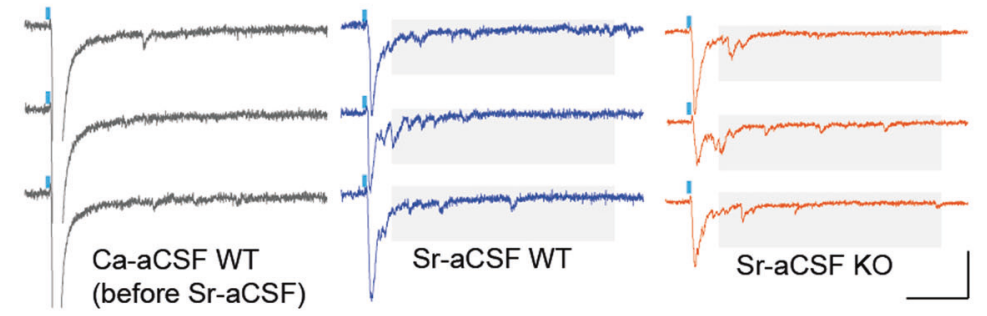

d

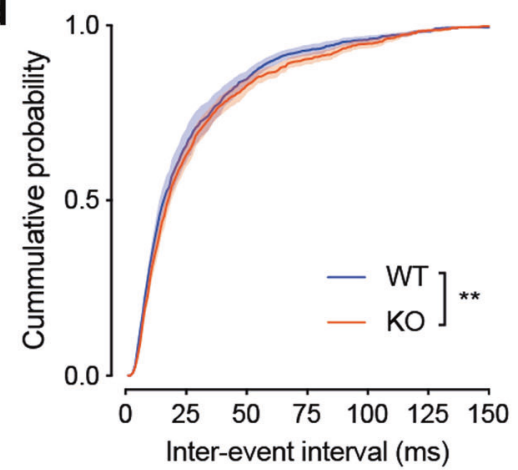

e
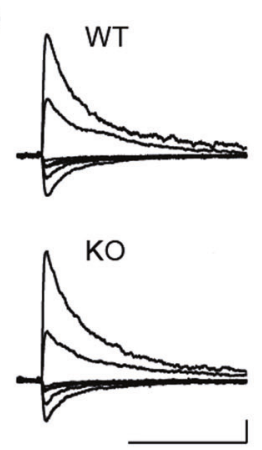

f

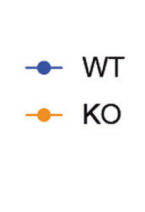

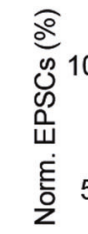
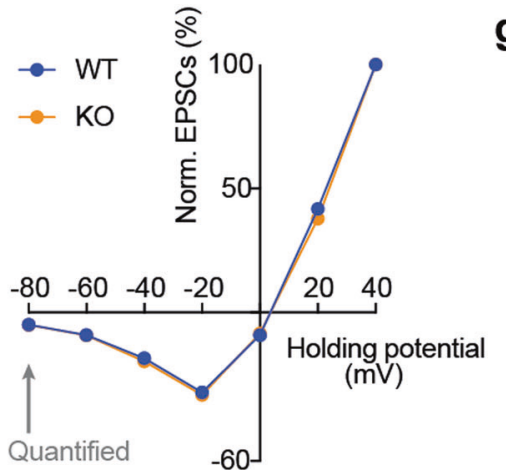

g

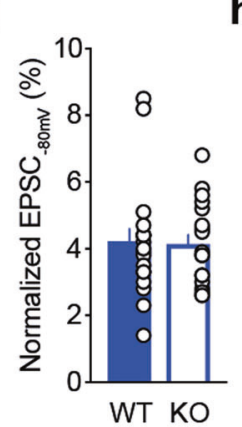

h

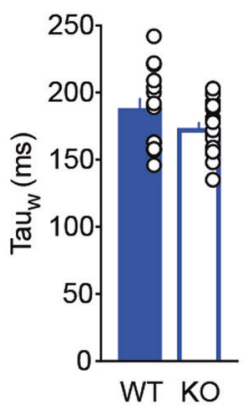

Fig. 4 Decreased AMPAR currents but no NMDAR subunit differences at the M1/M2-to-DLS synapses in Sapap3-KO mice. a Schematic of virus injection and location for patch-clamp recordings. $\mathbf{b}$ Three consecutive traces of recordings in $\mathrm{Ca}^{2+}$-containing artificial cerebrospinal fluid (aCSF; in gray; slice from WT) and in $\mathrm{Sr}^{2+}$-containing aCSF (in blue, WT; orange, KO). Light-blue lines indicate light stimulation. Scale bar is $50 \mathrm{~ms}, 100 \mathrm{pA}$. c Cumulative probability of EPSC amplitude in the presence of $\mathrm{Sr}^{2+}$. Amplitudes were significantly lower in KO than in WT mice. $P=0.0021$, Kolmogorov-Smirnov comparison. $N$ (cells) $=8 \mathrm{WT}, 12 \mathrm{KO}$. d Cumulative probability of inter-event intervals. Frequency was significantly lower in KO than in WT mice. $P=0.0086$, Kolmogorov-Smirnov comparison. $N$ (cells) $=8$ WT, 12 KO. e Representative traces of current-voltage $(I / V)$ relationship of NMDA receptor currents. Scale bar is $300 \mathrm{~ms}, 50 \mathrm{pA}$. $\mathrm{f}$ Current/voltage curves for two representative cells. g NMDAR EPSCs at $-80 \mathrm{mV}$ holding potential normalized to the EPSCs at $+40 \mathrm{mV}$ holding potential did not differ between WT and KO mice. $P=0.91$, nonparametric $t$-test. $N$ (cells) $=18 \mathrm{WT}, 18 \mathrm{KO}$. $\mathbf{h}$ Decay constant (weighted tau; Tau $\mathrm{w}_{\mathrm{w}}$ ) of NMDAR EPSCs recorded at $+40 \mathrm{mV}$ holding potentials did not differ between WT and KO mice. $P=0.11$, unpaired $t$-test. $N$ (cells) $=14$ WT, 18 KO. Data are mean \pm SEM.

littermates (Fig. 4c). Furthermore, frequency of inter-event interval of unitary events was decreased in Sapap3-KO (Fig. 4d), indicating that lower neurotransmitter release or lower numbers of synapses in the Sapap3-KO mice add to the synaptic weakening from reduced AMPAR currents. For OFC-to-cDS synapses we did not find decreased AMPAR amplitudes of unitary events (Fig. S4a, b), as indicated by $\mathrm{A} / \mathrm{N}$ ratios that were not different from WT controls. However, frequency of interevent interval of unitary events was decreased in Sapap3-KO at OFC-to-cDS (Fig. S4c), indicating that synaptic components other than the number of functional AMPAR per synapses weaken OFC-to-cDS control.

Next, we assessed NMDAR subunit composition at M1/M2-toDLS synapses, since NMDAR single-channel conductance is linked to NMDAR subunit composition [30]. Potential genotype differences in subunit composition could therefore alter the amplitude of NMDAR currents, contributing to $\mathrm{A} / \mathrm{N}$ changes. We recorded pharmacologically isolated NMDAR currents at different holding potentials (Fig. $4 \mathrm{e}, \mathrm{f}$ ) to test for the presence of GluN2C/D or GluN3 subunits, which would be indicated by increased conductance at $-80 \mathrm{mV}$ holding potential. No genotype differences were evident in this experiment, showing that Sapap3-KO mice do not have aberrant expression of GluN2C/D or GluN3 subunits at M1/M2-to-DLS synapses (Fig. 4g). Decay kinetics (weighted tau; $\mathrm{Tau}_{\mathrm{w}}$ ) of NMDAR currents can give information about relative abundance of the subunits GluN2A and GluN2B, but there were no genotype differences in $\mathrm{Tau}_{\mathrm{w}}$ (Fig. 4h).

These investigations imply that a reduction of AMPAR currents underlies the reduced $A / N$ ratio at M1/M2-to-DLS synapses, reflecting reduced synaptic strength. We did not find genotype differences in NMDAR function that are expressed through subunit composition. 


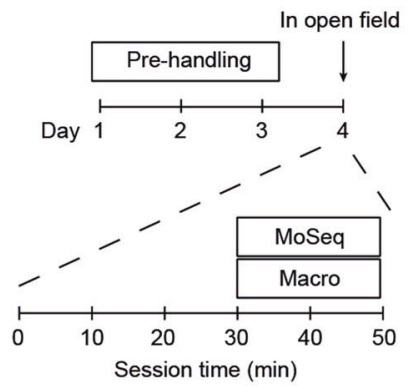

b

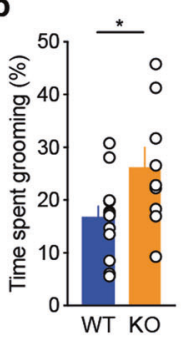

C

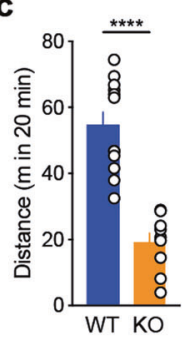

d

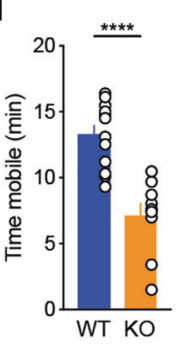

e

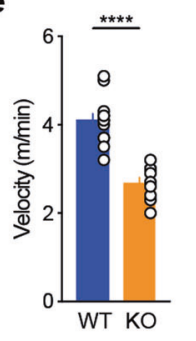

f

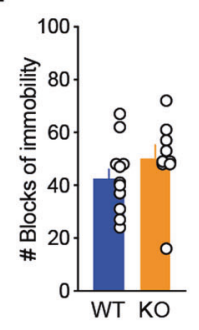

g

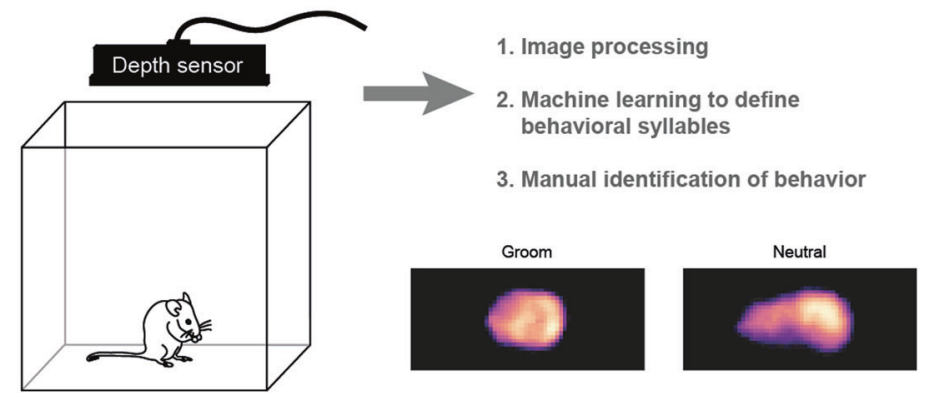

i

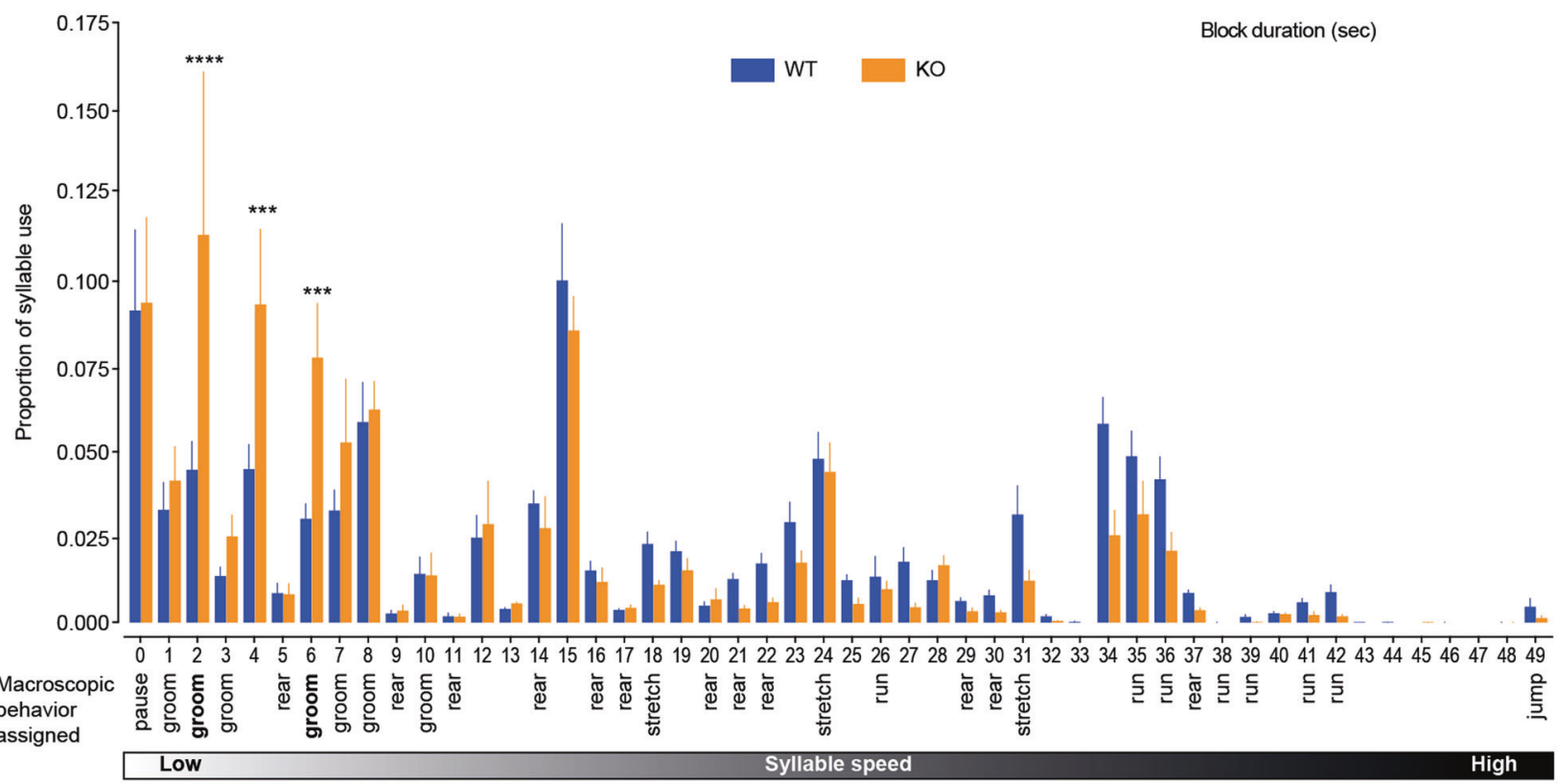

Fig. 5 Locomotion phenotypes are evident in Sapap3-KO mice by conventional behavioral analysis and quantification of sub-second behavioral syllables. a Experimental paradigm for behavioral analysis. "Macro" indicates conventional locomotor analysis and manual scoring of grooming, "MoSeq" indicates unsupervised motion sequencing. b Time spent grooming differed between WT and KO. Unpaired $t$-test, $p=$ 0.038. $N=12 \mathrm{WT}, 9 \mathrm{KO}$. c Distance traveled in the open field was significantly less in KO mice. Unpaired $t$-test, $p=2 \times 10^{-6} ; N=12 \mathrm{WT}, 9 \mathrm{KO}$. d Time mobile was significantly reduced in KO mice. Unpaired $t$-test, $p=5 \times 10^{-5} ; N=12 \mathrm{WT}, 9 \mathrm{KO}$. e Velocity during mobility time was significantly decreased in KO mice. Unpaired $t$-test, $p=3 \times 10^{-6} ; N=12 \mathrm{WT}, 9 \mathrm{KO}$. f Number of blocks in immobility did not differ between WT and KO. Unpaired $t$-test, $p=0.212 ; N=12$ WT, 9 KO. g Illustration of MoSeq behavioral set-up and work-flow for MoSeq analysis. Color images illustrate a screen shot from a "groom" and an unlabeled, neutral syllable. $\mathbf{h}$ Distribution of duration of all syllable blocks. In total, $93.8 \%$ of all blocks had a duration of less than $1 \mathrm{~s}$. The graph shows $99.6 \%$ of all values; $0.4 \%$ of the blocks had a duration of $>3 \mathrm{~s}$. i Proportion of use of the 50 behavioral syllables for WT and KO animals. Where clearly identifiable, labels of macroscopic behavior were post-hoc assigned manually. Syllables were sorted from left to right according to syllable speed. Three syllables were significantly used more by Sapap3-KO, compared to WT mice. Two-way ANOVA with significant interaction $\left(F(49,950)=2.252 ; p=3 \times 10^{-6}\right)$, Sidak post-hoc $p=3 \times 10^{-8}($ syllable 2$), p=6.3 \times$ $10^{-4}$ (syllable 4$)$, and $p=9.6 \times 10^{-4}$ (syllable 6). $N=12$ WT, 9 KO. Data are mean \pm SEM.

Motor phenotype in Sapap3-KO mice

Previously we made the observation that young adult Sapap3-KO mice have lower locomotor activity in an open-field arena [15]. For a more detailed locomotor analysis we assessed here motor behavior of young adult mice in a novel open-field arena (Fig. 5a). Like in the experiment described above where mice were tested in an empty cage (Fig. 1b), Sapap3-KO mice spent significantly more time grooming than WT littermates in the novel open field after an 
initial exploration phase of $30 \mathrm{~min}$ (Fig. 5b) as well as during the first 20 min of testing (Fig. S5). Furthermore, Sapap3-KO mice covered less distance during the exploration of a novel arena (Fig. 5c) and spent less time mobile, compared to WT littermates (Fig. 5d), but locomotion and grooming did not correlate (Fig. S6). Interestingly, velocity of forward movement (not including time immobile) was also significantly decreased in Sapap3-KO mice compared to WT littermates (Fig. 5e), but we found similar numbers of immobility events (Fig. 5f), which suggests that decreased velocity does not arise from an increased drive to stop for grooming. We conclude that grooming does not fully account for hypolocomotion, but that Sapap3-KO mice exhibit a general slowness of forward movements. Similar to grooming (Fig. 1b, c), hypolocomotion did not increase with age in mice tested between 7 and 28 weeks of age (Fig. S7).

To further probe this motor phenotype, we assessed exploratory behavior on a sub-second time scale using a novel, unsupervised machine learning technique (MoSeq) [25]. The goal of this technique is to automatically dissect behavior into syllables, allowing to compare the behavioral repertoire between conditions. Processed 3D videos of the open-field sessions (same as in Fig. $5 a-f$ ) and unsupervised machine learning yielded a profile of behavioral syllables (Fig. $5 \mathrm{~g}$ ). The machine learning procedure was set to segment behavioral motion into 50 behavioral syllables. We achieved sub-second resolution of behavior, as $93.8 \%$ of the syllable blocks lasted less than $1 \mathrm{~s}$ (Fig. 5h). To compare the use of behavioral syllables between Sapap3-KO and WT littermates during exploration of the open field, we quantified the proportional duration of syllable use for every mouse. For illustration we sorted syllables according to the speed of the mouse center point during the respective syllables, with speed increasing from left to right (Fig. 5i). Three experimenters independently labeled 31 of the 50 syllables post-hoc with clearly identifiable "macroscopic" behavior, such as grooming or running. Consistent with the lower velocity detected with the conventional locomotion analysis, behavior of Sapap3-KO was composed of more of the slower syllables than the behavior of WT animals. The cumulative proportional use of the ten slowest syllables was significantly greater in Sapap3-KO mice (mean \pm SD was $0.57 \pm 0.16$ for Sapap3-KO and $0.36 \pm 0.10$ WT; $p=0.0018, t$-test), whereas the cumulative proportional use of the ten fastest syllables was significantly smaller in the Sapap3-KO mice, compared to WT littermates (mean \pm SD was $0.0076 \pm 0.0043$ for Sapap3-KO and $0.022 \pm 0.018$ for WT; $p=$ $0.03, t$-test). All of the syllables used by Sapap3-KO were also used by WT, indicating that genotype differences were quantitative, but not qualitative such that certain motifs (e.g., related to special gait) would exclusively occur in the KO. Three syllables (\# 2, 4, 6) were significantly more frequently used in Sapap3-KO than in WT littermates. We identified syllable 2 and 6 as grooming. In a plot of the most frequent syllable transitions in Sapap3-KO mice (Fig. S8) syllable 4 appears as an intermediate syllable from "run" to "stretch" and might therefore be a syllable used in the transition of change in movement. Overall, our behavioral findings revealed movement abnormalities caused by the absence of SAPAP3, which might be caused by a disturbance in motor circuits, evident here by decreased strength at M1/M2to-DLS synapses.

\section{DISCUSSION}

We show that Sapap3-KO mice, a mouse model widely used to study OCD, groomed excessively already in early adulthood, without significant increase of grooming phenotype between 7 weeks and 6 months of age. We found that, in young adult mice at 2-4 months of age, synapses of M1/M2-to-DLS and Cg1/M2-toDMS projections were altered and exploratory locomotion was slower.
In humans, OCD symptoms typically appear relatively early in life with a mean onset at 19.5 years of age [31]. Previous studies typically used middle-aged Sapap3-KO mice at about 6 months of age, in order to capture OCD-like behavior shortly before the onset of skin lesions. However, since constitutive KO of Sapap3 causes synaptic deficits already in preadolescence [9, 19-21], we hypothesized that excessive grooming behavior must manifest early in life, which we confirmed here. Skin lesions might thus be a consequence of life-long excessive grooming, rather than of a sudden onset or worsening of the grooming phenotype at advanced age.

Grooming in WT mice is highly sensitive to experimental conditions including stressful situations such as a novel environment or exposure to bright light [32]. In contrast, excessive grooming in Sapap3-KO mice has been consistently observed across experimental conditions, including testing during light cycle $[9,12,13]$ and during the dark period $[9,10,17,33]$, which shows the robustness of the phenotype. A previous study demonstrates the accuracy of the experimenter-trained classifier JABBA to automatically score grooming in Sapap3-KO mice [10]. MoSeq is also a machine learning-based approach, but not per se designed to replace experimenter scoring of behavior, since it automatically segments behavior into dynamical regimes, i.e., syllables, which may not fit intuitive description by humans [25]. Nevertheless, our results indicate that MoSeq can be used to quantify grooming, as MoSeq grooming syllables correlated well with manual scoring (Fig. S9). Note that the MoSeq analysis resulted in higher grooming scores than manual analysis, since with manual scoring we considered grooming bouts of $>2 \mathrm{~s}$, whereas MoSeq has sub-second resolution.

Synaptic deficits in the DLS of Sapap3-KO mice have been investigated in-depth in preadolescence (postnatal days 21-25) [19-21]. In the present study we extend the characterization by demonstrating the corticostriatal synaptic deficit in adult mice. Using optogenetic projection targeting, we found that the M1/M2 corticostriatal connections are a key locus of the Sapap3-KO synaptic pathology, expressed by reduced AMPAR transmission, reducing the efficacy of synaptic transmission compared to WT mice. A limitation of our study is that we did not establish a direct causal link between synaptic deficits and behavioral phenotypes (Supplementary text; Fig. S10). Striatal DA levels affect vigor of movements [34], but no alterations in striatal DA concentrations in Sapap3-KO mice have been observed in tissue homogenates [35]. Therefore, it is likely that M1/M2-to-DLS synaptic dysfunction, and not altered DA levels, causes the locomotion phenotype of Sapap3-KO mice. Much attention has been given to excessive grooming in the Sapap3-KO mice, which is a motor output caused by the lack of SAPAP3 in the striatum and has compulsive traits since it leads to skin lesions $[9,36]$. Other potential motor phenotypes, such as the hypolocomotion we report here, have received far less attention, probably because there is no apparent link to cardinal symptoms of OCD. Clearly, hypolocomotion as bradykinesia is not a symptom of OCD. It is however conceivable that SAPAP3 mutations in humans elicit motor symptoms similar to the KO mouse model, but more subtle due to the heterozygous nature of the mutations in humans [7]. There are clinical reports of motor abnormalities in OCD patients [37]. Primary dysfunctions are indicated by neurological soft signs (deviations from average performance in tests assessing coordination, sensory integration and involuntary movements) that are more prevalent in $O C D$ patients than in healthy controls [37-40]. Although debated [41], there is evidence for genuine motor slowing in tests of executive function $[42,43]$. Slowness can also result from interference of obsessions with a task [44] or impaired decision making [45]. Nevertheless, we cannot exclude that slow locomotion is an epiphenomenon in the mouse model, simply arising from abnormal synaptic composition due to the constitutive homozygous KO of Sapap3. Further research is required to comprehend 
whether a link between the clinical symptoms and hypolocomotion in Sapap3-KO mice exists.

With Cg1/M2-to-DMS synapses showing decreased $\mathrm{A} / \mathrm{N}$ ratios in Sapap3-KO, we identified a second input affected by synaptic deficits. Altered synaptic properties at this input could underlie OCD-like behavioral inflexibility leading to aberrant habit formation [15] since lesioning the M2 impairs goal-directed behavior [46]. We did not follow up in detail on the directionality of change in $\mathrm{A} / \mathrm{N}$ ratio for $\mathrm{Cg} 1 / \mathrm{M} 2$-to-DMS synapses, however, comparison of absolute amplitudes suggested increase in both AMPAR and NMDAR with NMDAR changes outranging AMPAR currents. The significance of this comparison is limited by the lack of control for the number of stimulated synapses. The observation is nevertheless worth noting, since a similar finding in the Sapap3-KO model has been reported for the anterior secondary motor cortex (aM2) where AMPAR and NMDAR currents were increased with a net decreased $A / N$ ratio [22]. Another projection which is implicated in habit formation is the OFC-to-DS projection $[47,48]$ which we found unaltered. This result is in contrast with a recent study that showed in 8-9 weeks old Sapap3-KO mice that the OFC projection to the DS is weakened [22]. The viral spread of our experimental preparation leads to weak, but probably functional ChR2 expression in the aM2 (Fig. S2e). For the projection from the anterior aM2 to the DS increased AMPAR responses have been shown [22]. ChR2 expression that covers the OFC and aM2 could therefore cancel out projection-specific deficits if they are opposing. Such a confound cannot be fully excluded in our study. However, the expression in the aM2 was clearly weaker than in the OFC and we recorded cells in the medial part of the central striatum (Fig. S2e), where OFC terminals dominate over anterior secondary motor cortex terminals [22]. Furthermore, opposing roles of mouse medial/ventral and lateral OFC have been shown. Compulsive grooming can be induced by optogenetically increasing medial/ventral OFC-to-DS pathway activity [49]. In contrast, lateral OFC-to-DS projections seem to be hypoactive in Sapap3-KO mice, since optogenetic stimulation of the lateral OFC reduces compulsive grooming [11]. We cannot exclude that our approach to express ChR2 in the OFC with viral spread throughout the ventral and lateral portion of the OFC might have masked potential subregion-specific effects of the OFC.

In conclusion, we report here behavioral phenotypes that coexist with projection-specific corticostriatal deficits in young adult Sapap3-KO mice and showed that the extent of grooming phenotype remains constant across adulthood. Sapap3-KO mice seem well-suited to study the impact of corticostriatal synaptic deficits on motor output in OCD and related disorders.

\section{FUNDING AND DISCLOSURE}

This study was supported by the Swiss National Science Foundation (LDS; grant numbers P3P3PB_164751 and PZ00P3_174178) and the Fondation Privée des Hôpitaux Universitaires Genève $(\mathrm{CL}) . \mathrm{CL}$ is a member of the scientific advisory boards of the Phénix Foundation (Geneva) and the International research in paraplegia (IRP) Foundation (Zurich). LCH, MMS, JC, MCC, VP, and LDS declare no competing interests.

\section{ACKNOWLEDGEMENTS}

The authors would like to thank Agnès Hiver and Sébastien Pellat for excellent laboratory assistance and technical support

\section{AUTHOR CONTRIBUTIONS}

LDS, LCH, JC, MCC, and VP performed experiments. MMS implemented and performed MoSeq analysis. LDS and CL conceptualized and supervised the study. LDS wrote the paper. All authors contributed to and approved the final paper.

\section{ADDITIONAL INFORMATION}

Supplementary Information accompanies this paper at (https://doi.org/10.1038/ s41386-020-0747-3)

Publisher's note Springer Nature remains neutral with regard to jurisdictional claims in published maps and institutional affiliations.

\section{REFERENCES}

1. Gillan CM, Robbins TW. Goal-directed learning and obsessive-compulsive disorder. Philos Trans R Soc Lond B Biol Sci. 2014;369:1655.

2. Graybiel AM, Rauch SL. Toward a neurobiology of obsessive-compulsive disorder. Neuron. 2000;28:343-7.

3. Park H, Popescu A, Poo MM. Essential role of presynaptic NMDA receptors in activitydependent BDNF secretion and corticostriatal LTP. Neuron. 2014;84:1009-22.

4. Hunnicutt BJ, Jongbloets BC, Birdsong WT, Gertz KJ, Zhong H, Mao T. A comprehensive excitatory input map of the striatum reveals novel functional organization. Elife. 2016;5:e19103.

5. Graybiel AM, Aosaki T, Flaherty AW, Kimura M. The basal ganglia and adaptive motor control. Science. 1994:265:1826-31.

6. Rasmussen $A H$, Rasmussen $H B$, Silahtaroglu A. The DLGAP family: neuronal expression, function and role in brain disorders. Mol Brain. 2017;10:43.

7. Zuchner S, Wendland JR, Ashley-Koch AE, Collins AL, Tran-Viet KN, Quinn K, et al. Multiple rare SAPAP3 missense variants in trichotillomania and OCD. Mol Psychiatry. 2009;14:6-9.

8. Bienvenu OJ, Wang Y, Shugart YY, Welch JM, Grados MA, Fyer AJ, et al. Sapap3 and pathological grooming in humans: results from the $O C D$ collaborative genetics study. Am J Med Genet B Neuropsychiatr Genet. 2009;150B:710-20.

9. Welch JM, Lu J, Rodriguiz RM, Trotta NC, Peca J, Ding JD, et al. Cortico-striatal synaptic defects and OCD-like behaviours in Sapap3-mutant mice. Nature.2007; 448:894-900.

10. van den Boom BJG, Pavlidi P, Wolf $\mathrm{CJH}$, Mooij AH, Willuhn I. Automated classification of self-grooming in mice using open-source software. J Neurosci Methods. 2017;289:48-56.

11. Burguiere $E$, Monteiro $P$, Feng G, Graybiel AM. Optogenetic stimulation of lateral orbitofronto-striatal pathway suppresses compulsive behaviors. Science 2013;340:1243-6.

12. Ade KK, Wan Y, Hamann HC, O'Hare JK, Guo W, Quian A, et al. Increased metabotropic glutamate receptor 5 signaling underlies obsessive-compulsive disorder-like behavioral and striatal circuit abnormalities in mice. Biol Psychiatry. 2016;80:522-33.

13. Manning EE, Dombrovski AY, Torregrossa MM, Ahmari SE. Impaired instrumental reversal learning is associated with increased medial prefrontal cortex activity in Sapap3 knockout mouse model of compulsive behavior. Neuropsychopharmacology. 2019;44:1494-504.

14. van den Boom BJG, Mooij AH, Miseviciute I, Denys D, Willuhn I. Behavioral flexibility in a mouse model for obsessive-compulsive disorder: Impaired Pavlovian reversal learning in SAPAP3 mutants. Genes Brain Behav. 2019;18:e12557.

15. Hadjas LC, Luscher C, Simmler LD. Aberrant habit formation in the Sapap3knockout mouse model of obsessive-compulsive disorder. Sci Rep. 2019;9:12061.

16. Ehmer I, Feenstra M, Willuhn I, Denys D. Instrumental learning in a mouse model for obsessive-compulsive disorder: impaired habit formation in Sapap3 mutants. Neurobiol Learn Mem. 2020;168:107162.

17. Pinhal CM, van den Boom BJG, Santana-Kragelund $F$, Fellinger $L$, Bech $P$, Hamelink $R$, et al. Differential effects of deep brain stimulation of the internal capsule and the striatum on excessive grooming in Sapap3 mutant mice. Biol Psychiatry. 2018;84:917-25.

18. Todorov G, Mayilvahanan K, Ashurov D, Cunha C. Amelioration of obsessivecompulsive disorder in three mouse models treated with one epigenetic drug: unraveling the underlying mechanism. Sci Rep. 2019;9:8741.

19. Chen M, Wan Y, Ade K, Ting J, Feng G, Calakos N. Sapap3 deletion anomalously activates short-term endocannabinoid-mediated synaptic plasticity. J Neurosci. 2011;31:9563-73.

20. Wan Y, Feng G, Calakos N. Sapap3 deletion causes mGluR5-dependent silencing of AMPAR synapses. J Neurosci. 2011;31:16685-91.

21. Wan Y, Ade KK, Caffall Z, Ilcim Ozlu M, Eroglu C, Feng G, et al. Circuit-selective striatal synaptic dysfunction in the Sapap3 knockout mouse model of obsessivecompulsive disorder. Biol Psychiatry. 2014;75:623-30.

22. Corbit VL, Manning EE, Gittis AH, Ahmari SE. Strengthened inputs from secondary motor cortex to striatum in a mouse model of compulsive behavior. J Neurosci. 2019;39:2965-75.

23. Luscher C, Malenka RC. NMDA receptor-dependent long-term potentiation and long-term depression (LTP/LTD). Cold Spring Harb Perspect Biol. 2012;4: a005710. 
24. Kindler S, Rehbein M, Classen B, Richter D, Bockers TM. Distinct spatiotemporal expression of SAPAP transcripts in the developing rat brain: a novel dendritically localized mRNA. Brain Res Mol Brain Res. 2004;126:14-21.

25. Wiltschko $A B$, Johnson MJ, lurilli G, Peterson RE, Katon JM, Pashkovski SL, et al. Mapping sub-second structure in mouse behavior. Neuron. 2015;88:1121-35.

26. Mathis A, Mamidanna P, Cury KM, Abe T, Murthy VN, Mathis MW, et al. DeepLabCut: markerless pose estimation of user-defined body parts with deep learning. Nat Neurosci. 2018;21:1281-89.

27. Abbas W, Masip Rodo D. Computer methods for automatic locomotion and gesture tracking in mice and small animals for neuroscience applications: a survey. Sensors. 2019;19:3274.

28. Pascoli V, Hiver A, Van Zessen R, Loureiro M, Achargui R, Harada M, et al. Stochastic synaptic plasticity underlying compulsion in a model of addiction. Nature.2018;564:366-71.

29. Paxinos G, Franklin KBJ. The mouse brain in stereotaxic coordinates. Compact 2nd ed. Amsterdam; Boston: Elsevier Academic Press; 2004.

30. Yuan $T$, Bellone $C$. Glutamatergic receptors at developing synapses: the role of GluN3A-containing NMDA receptors and GluA2-lacking AMPA receptors. Eur J Pharmaol. 2013;719:107-11.

31. Ruscio AM, Stein DJ, Chiu WT, Kessler RC. The epidemiology of obsessivecompulsive disorder in the National Comorbidity Survey Replication. Mol Psychiatry. 2010;15:53-63.

32. Kalueff AV, Stewart AM, Song C, Berridge KC, Graybiel AM, Fentress JC. Neurobiology of rodent self-grooming and its value for translational neuroscience. Nat Rev Neurosci. 2016;17:45-59.

33. Ehmer I, Crown L, van Leeuwen W, Feenstra M, Willuhn I, Denys D. Evidence for distinct forms of compulsivity in the SAPAP3 mutant-mouse model for obsessivecompulsive disorder. eNeuro. 2020;7:ENEURO.0245-19.2020.

34. Albin RL, Young AB, Penney JB. The functional anatomy of basal ganglia disorders. Trends Neurosci. 1989;12:366-75.

35. Wood J, LaPalombara Z, Ahmari SE. Monoamine abnormalities in the SAPAP3 knockout model of obsessive-compulsive disorder-related behaviour. Philos Trans R Soc Lond B Biol Sci. 2018;373:20170023.

36. Mahgoub M, Adachi M, Suzuki K, Liu X, Kavalali ET, Chahrour MH, et al. $\mathrm{MeCP} 2$ and histone deacetylases 1 and 2 in dorsal striatum collectively suppress repetitive behaviors. Nat Neurosci. 2016;19:1506-12.
37. Hirjak D, Meyer-Lindenberg A, Fritze S, Sambataro F, Kubera KM, Wolf RC. Motor dysfunction as research domain across bipolar, obsessivecompulsive and neurodevelopmental disorders. Neurosci Biobehav Rev. 2018;95:315-35.

38. Bihari K, Pato MT, Hill JL, Murphy DL. Neurologic soft signs in obsessivecompulsive disorder. Arch Gen Psychiatry. 1991;48:278-9.

39. Hollander E, Schiffman E, Cohen B, Rivera-Stein MA, Rosen W, Gorman JM, et al. Signs of central nervous system dysfunction in obsessive-compulsive disorder. Arch Gen Psychiatry. 1990;47:27-32.

40. Mergl R, Mavrogiorgou P, Juckel G, Zaudig M, Hegerl U. Effects of sertraline on kinematic aspects of hand movements in patients with obsessive-compulsive disorder. Psychopharmacol. 2004;171:179-85.

41. Kuelz AK, Hohagen F, Voderholzer U. Neuropsychological performance in obsessive-compulsive disorder: a critical review. Biol Psychol. 2004;65: 185-236.

42. Snyder HR, Kaiser RH, Warren SL, Heller W. Obsessive-compulsive disorder is associated with broad impairments in executive function: a meta-analysis. Clin Psychol Sci. 2015;3:301-30.

43. Tukel R, Gurvit H, Ertekin BA, Oflaz S, Ertekin E, Baran B, et al. Neuropsychological function in obsessive-compulsive disorder. Compr Psychiatry. 2012;53: 167-75.

44. Hymas N, Lees A, Bolton D, Epps K, Head D. The neurology of obsessional slowness. Brain. 1991;114:2203-33.

45. Benzina N, Mallet L, Burguiere E, N'Diaye K, Pelissolo A. Cognitive dysfunction in obsessive-compulsive disorder. Curr Psychiatry Rep. 2016;18:80.

46. Gremel CM, Costa RM. Premotor cortex is critical for goal-directed actions. Front Comput Neurosci. 2013;7:110.

47. Gremel CM, Chancey JH, Atwood BK, Luo G, Neve R, Ramakrishnan C, et al. Endocannabinoid modulation of orbitostriatal circuits gates habit formation. Neuron. 2016;90:1312-24.

48. Simmler LD, Ozawa T. Neural circuits in goal-directed and habitual behavior: Implications for circuit dysfunction in obsessive-compulsive disorder. Neurochem Int. 2019;129:104464.

49. Ahmari SE, Spellman T, Douglass NL, Kheirbek MA, Simpson HB, Deisseroth K, et al. Repeated cortico-striatal stimulation generates persistent OCD-like behavior. Science.2013;340:1234-9. 